\title{
Increasing Student Intrinsic Motivation And Self-Efficacy Through Gamification Pedagogy
}

James Banfield, Eastern Michigan University, USA

Brad Wilkerson, Eastern Michigan University, USA

\begin{abstract}
The aim of this study was to assess gamification as a method of experiential learning theory (ELT) on student motivation and self-efficacy to perform System Engineering/Information Assurance (IA) tasks. The study was a basic qualitative method, whereby data was collected via semi-structured interview and then analyzed for recurring themes and patterns. The students involved in the study were undergraduate students enrolled in system administration and security courses. We introduced ELT in early stages of curriculum in place of commonly used didactic methods of delivering theory. We compared the themes found in increased ELT classes with past didactic sections of the same courses. Data analysis revealed that increasing ELT in IA coursework at all levels of the curriculum increased both student intrinsic motivation and self-efficacy. This paper outlines gamification pedagogy used in 200 and 300 level postsecondary courses of system administration. Gathered results indicated high intrinsic motivation and self-efficacy from the students 96 interviewed. The paper will also present examples of gamification ELT lessons at each level of undergraduate study.
\end{abstract}

KEYWORDS: Gamification Pedagogy; Student Self-Efficacy; Intrinsic Motivation; Experiential Learning Theory

\section{INTRODUCTION}

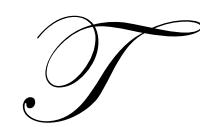

oday most university students sit and listen while taking notes as a professor delivers a lecture. This is traditional didactic education that is instructor centered. While there could be 10 to 100 human beings in the room, there is little to no human interaction. Exam time is the first chance most professors using this pedagogy can gauge how well students digested the delivered lecture information. Here, student motivation is extrinsic, focused on grade, employment or task rather than intrinsic motivation, which focuses on satisfaction, or pleasure in performing a task (Lei, 2010). This stems from a belief system that learning should feel much like work (Vesterbacka, 2013).

Research literature is heavy in claiming that American schools are not teaching enough, are not rigorous enough, and offer too much play (Ravitch, 2013; Sahberg, 2011; Zwaagsta, et al, 2010). On the contrary, American Schools are not playing enough and we are working too hard. The didactic approach that is so common in postsecondary education needs to be integrated with doing (Kolb, 1984). Experiential learning theory, or ELT, is active learning where the learning is student-centered activity. Gamification, an offshoot of ELT, is the combination of game components such as score, challenge, and achievement with learning objectives in an effort to motivate and engage the student (Deterding et al,2011).

The extrinsically motivated student attends class because they have to for attendance, grade or other external motivator (Ryan \& Deci, 2010). The intrinsically motivated (IM) student comes to class because they hunger for more information, they want to be there, they are involved and their self-efficacy soars. Classrooms must become student centric to reach IM goals, and gamification of learning objectives can be used to reach that target. Research on using gamification to drive educational goals outlined by Ryan \& Deci is sparse in System Engineering/Information Assurance (IA) courses (2010). The majority of studies (Engler, 2012; Muntean, 2011; Renaud \& Wagner, 2011) focus on the use of commercially available games, however this research investigates the 
creation of didactic learning objectives blended with gaming theory to increase intrinsic motivation and selfefficacy.

The problem of education is that we must convert student extrinsic motivation (EM) into intrinsic motivation (IM) in order to increase student self-efficacy (SE) to explore, participate and to reach true knowledge gain and nurture new innovative thought (Bandara 1977; Kolb 1984). In this research, we study how the use of gamification pedagogy across 200 and 300 level postsecondary courses in Information Assurance (IA) affect student IM and SE.

\section{Experiential Learning Theory, Motivation and Gamification}

\section{Experiential learning theory $(E L T)$}

ELT is not a new pedagogy as it was developed by Dr. David Kolb (1984) and built on the foundation methods established by education theory pioneers John Dewey, Kurt Lewin, and Jean Piaget. Kolb's ELT describes learning as a process whereby thoughts are formed then re-formed through experience, thus creating new knowledge and deeper understanding (Kolb, 1984). ELT, at the very core, is hands-on learning pedagogy that is student centric. Muntean (2011) further defined hands-on learning as an educational process that through practice, creates aptitude and deeper understanding that can lead to an increase in student intrinsic motivation. The ancient Chinese proverb, "Teach me and I will forget. Show me and I may remember. Involve me and I'll understand..." captures the central theme of why experiential learning is critical to education (unknown source).

ELT is commonplace in IA education research (Stockman \& Nylan, 2112; Cooper et al, 2010), however using gamification as the underpinning pedagogy to raise IM and SE in IA is sparse. Gamification is commonly used in business programs in the form of case study and in elementary schools to engage new learners, but is just breaking surface in other disciplines. Gamification does not simply imply creating a game, it is a pedagogy used to make the student more engaged without deflation of educational credibility (Muntean, 2011).

\section{Motivation and self-efficacy}

Motivation to learn is seen in the form of student persistence, curiosity, and performance (Lei, 2010). Intrinsic motivation (IM) is defined as participating for pleasure, or satisfaction derived from performing an act. As IM increases, self-efficacy (SE) to complete tasks is learned and active processes begin which lead to deeper understanding and the creation of aptitude (Chentanez at al., 2004). Bandura defined SE as personal belief of one's own capability to execute strategy to attain designated goals (1977). Zimmerman (1997) found SE to be highly correlated with student IM, while Schunk \& Hanson found that increases in student effort and rate of performance increased with higher SE (1987).

Extrinsic motivation (EM) also has merit in college level coursework as students learn for recognition, grades, and other performance metrics. However, the EM student has many drawbacks such as minimal effort to achieve goals, stopping of learning processes once goal is achieved, lower SE, and less cooperative behavior (Lei). Bandura (1977) hypothesized that self-efficacy affects an individual's choice of activities, level of effort, and persistence in completing tasks. Bandura states that people who have a low sense of efficacy for accomplishing a task may avoid it all together. On the other hand, individuals with high SE are noticed to work harder and endure longer when they meet complications (Ibid). For these reasons, our research is aimed at increasing SE and IM though the usage of gamificiation.

\section{Gamification}

Gamification is ELT pedagogy. In the most simplistic terms, gamification in education is the use of game components such as score, challenge, and achievement to learning objectives, in an effort to motivate and engage the student (Deterding et al., 2011). Methods deployed range from capture the flag events, quiz challenges, debate, use of leader boards and point gathering. The options for gamification are limited only by instructor creativity and trigger more efficient and engaged learning behavior (Muntean, 2011). 
Competition, either against one's self or against a peer group is the driving force behind the success of gamification. The learning effects of competition are based in social interaction and student desire to see their name at the top of a scored list (Conklin, 2006), or by comparing their personal score to peer achievement. Extrinsic motivation rewards, achieved through deliberate competitive goals, are an effective tool until intrinsic motivation can evolve (Rimm, 1986). As students begin to grow in self-efficacy the scoreboard will provide the metric that makes competition an effective learning vehicle. Students will be exposed to learning pace, comparative analysis, and experience motivation to move deeper into a topic. According to Lam, Yim and Chueng, competition has a constructive effect on participation and knowledge forming resulting in higher learning through social pressure to achieve (2004).

Research questions

- Does gamification pedagogy in IA coursework increase intrinsic motivation compared to didactic pedagogy?

- Does gamification pedagogy in IA coursework increase self-efficacy compared to didactic pedagogy?

\section{RESEARCH MODEL}

\section{Method}

The focus of the study was to understand the perspective of the students involved in the study. Thus, a direct observation method using loose interviewing was chosen as a qualitative method. The researcher was embedded into class exercises and generally performed the same function as others in the setting, so as to gain a deeper understanding of the student perceptions through comments and observation (Given, 2008). The participant observation method is typically accomplished by using a variety of methods including direct observation, informal interviewing, and open discussion (Given, 2008; Jorgensen, 1989). The researcher was embedded in other class assignments to build trust and help mitigate the issue of changing student behavior caused by researcher presence. Interviewing was performed in the format of discussion, or group conversation, to avoid a structure that can lead to bias (Krueger, 1998; Rubin et al. 2004). The group responses were then analyzed to identify key themes. A word tree was developed in order to visualize the most commonly used words and to examine the connections between IM, EM, and SE. Themes were identified and compared to already accepted tools that measure IM, EM and SE. The gamification classes were taught using the outlined "games" below, while the didactic class had lectures only. We discussed competition and score boarding after both courses completed their work.

\section{Participation}

Participants included students from two sections of an introduction to computer networking course (210) and two sections of a systems administration (344) course in a large public university in the Northern United States. A total of 96 students participated in the research.

Class set up: IA 210

The 210 classes were first taught didactic methods of solving complex subnet problems. This involved algebraic computation and problem solving to write out possible network addresses. The didactic exercise ended here. Students in the gamification section continued the lesson of subnetting and were taught how to use Nmap, a tool used for scanning subnets. Students used the gathered Nmap information to find clues hidden on the network.

\section{Gamification setup}

Students were provided an IP address of a node on a given network and expected to calculate the subnet mask, range of available IP addresses and then use Nmap to find the running HTML service. 
For example, given the IP address 10.1.5.50/29, students had to use subnet math (no on-line calculators) to decipher the following:

Subnet Mask: 255.255.255.240

Subnet number: 6

Available IP range: 10.1.5.49 -10.1.5.54/29

Students then had to change the static IP of their own machine to the appropriate network, then Nmap the appropriate range to find the web server. Once found, the web server address could be typed into a browser where the next node address would be revealed along with a clue about a selected famous individual.

Seven web servers were configured using VMware ESXI server, each in a different subnet and each with a different set of clues. Clues included the IP address of a node on the next network. As students progressed through the seven web servers, they were instructed to switch between Windows 7 and CentOS clients.

The whiteboard in the front of the room showed a scoreboard of how many students had discovered the clues and a tally of how many peers had found all seven web servers. The hunt for the clues and the knowledge of peer success motivated the classroom to endeavor to finish the task. Competition has a constructive effect on participation and learning that will result in higher learning through social pressure to achieve (Burguillo, 2010).

Objectives of the subnet lesson for both didactic and gamification:

- $\quad$ Subnet a network

- $\quad$ Solve given nodes for subnet data (subnet number, mask, range, broadcast)

- $\quad$ Change static IP addresses in multiple operating systems

- $\quad$ Use NMap to identify running services on a network

Class set up: IA 344

IA 344 is not only a Microsoft Server administration class, but also a security class. Good security comes down to offense and defense, hackers and protectors, ultimately culminating in managing the risk presented by security issues (Wei, 2010). Students are taught via Socratic/didactic pedagogy; that is the lectures on security for the operating system are done via debate and discussion.

Students build Active Directory servers in VMware and install live network services such as DNS, NAP, NAC, DHCP and GPO. For this ELT lab, students are asked to build a working DNS and DHCP server that distributes IP addresses in a given scope. The work is then graded for administrative quality and correctness. This is done for both didactic and gamification deliveries.

For the gamification lesson and after completion of the administrative task, students are then asked to read a case study of a Microsoft breached server event. The case study does not reveal the root cause of the breach. Students are then asked to restore VMware snapshot 1 which is a replica of the server breached in the case study. Next, the student is tasked to review the new server and analyze the server security to solve the case study. They are told that there a minimum of five areas that will lead them to root cause.

These are the objectives of the gamification assignment (not shared with student):

- Attack surface - Web and FTP are installed, but not needed

- Firewall rules - should remove unused and constrain others

- Remove unused protocols/ports

- Review audit logs

- Verify User least privilege 
As students find security issues, they are asked to write them down for future grading and fix the issue. A public scoreboard tracks how many holes have been identified and by how many students. Upon successful completion of the security review, students are asked to write a brief root cause analysis and deliver to the instructor. Snapshot 2 can then be restored to allow the student to continue to work on a new problem, while other peers complete snapshot 1 . When all are finished, class discussion identifies the root cause and prevention methods. Each of the security holes is discussed, along with any other errors found by students.

\section{Interview/coded theme Results}

The student comments were collected during the exercise. Careful notes were taken for later coding of themes. Other data was collected at the completion of class in open discussion and coded for the similar themes. A word tree was built from the student comments to identify key themes. Both the gamification and didactic classes were asked the same open questions during the discussion:

- What is your feeling of the assignment?

- $\quad$ Do you feel that you have a firm grasp on the knowledge objectives?

- $\quad$ Do you feel you could "figure out" new problems in Administration?

- Which part of the lesson did you find most interesting?

- Would/did the scoreboard play a role in your work?

- Would/Did competition play a role in your work?

The questions above were designed to be conversation starters; careful attention was paid to insure no the conversation was not led in a prejudiced direction. Two faculty members participated in the discussion, one managing the dialogue while the other monitored for bias.

The data was then reviewed looking for themes and collating responses. For example, for the question "what is your feeling on the assignment..." students that answered cool, fun, or loved it, were all coded as positive response under the category of experiencing pleasure from the task. Lei's model of measuring Intrinsic and extrinsic motivation was used as the accepted measuring tool (2010).

\section{DISCUSSION}

In this study, we sought to test the usefulness of gamification as a teaching pedagogy in Information Assurance classes to increase intrinsic motivation and self-efficacy in students. This was a qualitative study on the usage of gamification as the underpinning of experiential learning theory (ELT) as the tool used to increase intrinsic motivation (IM) and self-efficacy (SE) to perform IA tasks.

\section{Intrinsic/Extrinsic motivation}

As seen in the student responses, intrinsic motivation increased dramatically with the introduction of gamification. The course taught with didactic pedagogy had only 2 students who found the exercise fun and only 3 students who were able to organize knowledge and relate it to existing knowledge (Lei, 2010). In the exercises that were taught using gamification, 25 found the work fun and 56 were able to tie the work to previous knowledge. An alarming rate of $92.2 \%$ of the students exposed to gamification responded in intrinsic motivation themes. Only $30.5 \%$ of the didactic students where intrinsically motivated. Burguillo states clearly that intrinsic motivation is a key element to achieved learning. Increased IM will prompt the student to engage in exploration, effort, and participation driven by curiosity and not explicit reward (2010).

Extrinsic motivation, whereby the student is motivated by grade, least effort needed, and external sources of motivation revealed themes that were an expectant opposite. A miniscule $.078 \%$ of the gamification students were motivated extrinsically, while the didactic class was .70\% externally motivated. 
Table 1: Intrinsic Motivation

\begin{tabular}{|c|c|l|l|}
\hline $\begin{array}{c}\text { Didactic } \\
\text { N=42 }\end{array}$ & $\begin{array}{c}\text { Gamification } \\
\text { N=54 }\end{array}$ & "Word tree" examples; Coded Comments & Intrinsic Themes Identified by Lei (2010) \\
\hline 2 & 25 & "Fun" & Experience pleasure in what they are doing \\
\hline 21 & 32 & Questions why a setting was made & Attends to instruction \\
\hline 2 & 43 & "Tough, but cool" & Perseverance \\
\hline 0 & 45 & "Another issue down" & Applies skills and knowledge to problem \\
\hline 0 & 25 & Tried "X" & Show creativity in action \\
\hline 12 & 44 & Why? What if? & $\begin{array}{l}\text { Regular evaluation or monitoring of own } \\
\text { progress }\end{array}$ \\
\hline 0 & 35 & "High score!!" & $\begin{array}{l}\text { Organize knowledge and relate it to existing } \\
\text { knowledge }\end{array}$ \\
\hline 3 & 11 & "This wasn't covered in lecture" & $\begin{array}{l}\text { Regular evaluation or monitoring of own } \\
\text { progress }\end{array}$ \\
\hline 23 & 74 & "How have people found 5 errors" & $\begin{array}{l}\text { Organize knowledge and relate it to existing } \\
\text { knowledge }\end{array}$ \\
\hline 3 & 56 & "Now the lecture makes sense" & Undertake more challenging aspects of a task \\
\hline 3 & 66 & "I found more then 5 errors" & Does not depend on tangible reward \\
\hline 2 & 43 & "Can we do more of this?" &
\end{tabular}

Table 2: Extrinsic Motivation

\begin{tabular}{|c|c|l|l|}
\hline $\begin{array}{c}\text { Didactic } \\
\mathbf{N}=\mathbf{4 2}\end{array}$ & $\begin{array}{c}\text { Gamification } \\
\mathbf{N}=\mathbf{5 4}\end{array}$ & \multicolumn{1}{|c|}{ "Word tree" examples; Coded Comments } & Extrinsic Themes Identified by Lei (2010) \\
\hline 27 & 4 & $\begin{array}{l}\text { " I could not evaluate and find errors in a } \\
\text { running system" }\end{array}$ & Low self-esteem \\
\hline 16 & 7 & "I'd try it for Extra credit" & $\begin{array}{l}\text { Receiving extremely rewards or } \\
\text { reinforcements (e.g. extra credit or bonus } \\
\text { points) }\end{array}$ \\
\hline 22 & 5 & $\begin{array}{l}\text { "Competition WOULD have been important } \\
\text { piece" }\end{array}$ & $\begin{array}{l}\text { Competition for tangible rewards (e.g. honors } \\
\text { and awards) }\end{array}$ \\
\hline 31 & 4 & "I'd do the work as a class" & Social reasons for learning \\
\hline 12 & 5 & Stupid/dumb, when will I use this & Learning compliance \\
\hline 31 & 14 & "Scoreboard WOULD have helped me" & $\begin{array}{l}\text { Competition for tangible rewards (e.g. honors } \\
\text { and awards) }\end{array}$ \\
\hline 23 & 3 & $\begin{array}{l}\text { "Would we have to find all 5 errors for } \\
\text { credit?" }\end{array}$ & Least effort needed \\
\hline
\end{tabular}

\section{Self-efficacy}

To measure self-efficacy we used the seminal chapter from Zimmerman's book Adolescents' development of personal agency: The role of self-efficacy beliefs and self-regulatory skill (2006). More specifically, we used Albert Bandura's chapter Guide for Constructing Self-efficacy Scales, which has been cited in other research over 1300 times (1997). Efficacy items should accurately reflect the construct. Self-efficacy is concerned with perceived capability. According to Bandura, the items should be phrased in terms of can do rather than will do as can is a judgment of capability; will is a statement of intention (1997).

Discussion questions/statements to study self-efficacy included:

- $\quad$ Can you figure out any assignment in Windows server?

- $\quad$ Can you finish assignments for 344 completely and on time?

- $\quad$ I feel I can accomplish untaught administration tasks.

- $\quad$ I feel I can help others with the course.

Students were asked to rank the comfort levels in each of the themes above. Specifically, the students were asked to pick a quartile $0-100$, and then provide their personal rank within the quartile. 
Self-efficacy (SE) is as personal confidence that one has to execute strategy to attain designated goals (Bandurra). Zimmerman (1997) found SE to be highly correlated with student intrinsic motivation, while Schunk \& Hanson found that increases in student effort and rate of performance increased with higher SE (1987). In our study, we found that student SE soared while being taught using gamification pedagogy. Consider the student selfconfidence in the statement, "I can figure out how to do anything in Windows server". In the gamification course, $90.3 \%$ of students answered in the 50-100 range, while $28.5 \%$ of the didactic class answered in the same range on the same statement. SE is a key ingredient to creating aptitude and gamification is a pedagogy that dramatically increases SE.

Table 3: Self-efficacy

\begin{tabular}{|c|c|c|c|c|c|}
\hline \multicolumn{2}{|c|}{ Gamification N=31 } & \multicolumn{2}{|c|}{ Didactic N=28 } \\
\hline Responses & Mean Score & Quartile & Bandura themes (1977) & Responses & Mean Score \\
\hline 0 & 0.0 & $\mathbf{0 - 2 5}$ & \multirow{2}{*}{ "I can figure out how to } & 7 & 21.2 \\
\hline 3 & 37.3 & $\mathbf{2 6 - 5 0}$ & \multirow{2}{*}{ do anything in Windows } & 13 & 38.5 \\
\hline 10 & 17.1 & $\mathbf{5 1 - 7 5}$ & server" & 6 & 62.2 \\
\cline { 5 - 6 } \cline { 5 - 6 } & 92.4 & $\mathbf{7 6 - 1 0 0}$ & & 2 & 80.2 \\
\hline
\end{tabular}

\begin{tabular}{|c|c|c|c|c|c|}
\hline \multicolumn{2}{|c|}{ Gamification $\mathbf{N}=31$} & \multirow[b]{2}{*}{ Quartile } & \multirow[b]{2}{*}{ Bandura themes (1977) } & \multicolumn{2}{|c|}{ Didactic $\mathbf{N}=\mathbf{2 8}$} \\
\hline Responses & Mean Score & & & Responses & Mean Score \\
\hline 0 & 0.0 & $0-25$ & \multirow{4}{*}{$\begin{array}{c}\text { "I can finish assignments } \\
\text { in } 344 \text { on time by } \\
\text { deadline" }\end{array}$} & 0 & 0.0 \\
\hline 0 & 0.0 & $26-50$ & & 7 & 41.3 \\
\hline 16 & 61.4 & $51-75$ & & 18 & 54.0 \\
\hline 15 & 93.2 & $76-100$ & & 6 & 81.2 \\
\hline
\end{tabular}

\begin{tabular}{|c|c|c|c|c|c|}
\hline \multicolumn{2}{|c|}{ Gamification $\mathbf{N}=\mathbf{3 1}$} & \multirow[b]{2}{*}{ Ouartile } & \multirow[b]{2}{*}{ Bandura themes (1977) } & \multicolumn{2}{|c|}{ Didactic $\mathrm{N}=28$} \\
\hline Responses & Mean Score & & & Responses & Mean Score \\
\hline 1 & 20.0 & $0-25$ & \multirow{4}{*}{$\begin{array}{c}\text { " I feel I have the } \\
\text { aptitude to evaluate } \\
\text { "untaught" } \\
\text { administration tasks }\end{array}$} & 4 & 24.0 \\
\hline 3 & 39.9 & $26-50$ & & 18 & 48.4 \\
\hline 15 & 65.5 & $51-75$ & & 4 & 35.5 \\
\hline 12 & 91.1 & $76-100$ & & 2 & 81.6 \\
\hline
\end{tabular}

\begin{tabular}{|c|c|c|c|c|c|}
\hline \multicolumn{2}{|c|}{ Gamification $\mathbf{N}=\mathbf{3 1}$} & & & \multicolumn{2}{|c|}{ Didactic $N=28$} \\
\hline Responses & Mean Score & Quartile & Bandura themes (1977) & Responses & Mean Score \\
\hline 2 & 22.2 & $0-25$ & \multirow{4}{*}{$\begin{array}{l}\text { "I can help others with } \\
\text { course tasks" }\end{array}$} & 3 & 4.2 \\
\hline 7 & 44.2 & $26-50$ & & 6 & 48.8 \\
\hline 17 & 67.8 & $51-75$ & & 14 & 51.5 \\
\hline 5 & 93.1 & $76-100$ & & 5 & 78.8 \\
\hline
\end{tabular}

\section{AUTHOR INFORMATION}

James Banfield is an Assistant Professor of Information Assurance (IA) and Program Coordinator at Eastern Michigan University, a Center of Academic Excellence sponsored by the National Security Agency. James is currently a PhD candidate in the IA program at EMU and will defend his dissertation in 2014. He has assisted the EMU IA program in acquiring over $\$ 500,000$ in pedagogy related funding from the Department of Defense since 2010. James has presented at multiple conferences on various security and education projects. Prior to joining Eastern Michigan, he spent over 20 years in private industry. Email: JBanfield@emich.edu

Brad Wilkerson is an Assistant Professor of Information Assurance (IA), a Center of Academic Excellence in Information Assurance education as designated by the National Security Agency. Prior to coming to EMU, Wilkerson was senior cyber security specialist contractor for DTE Energy from 2010-2011 and an information assurance specialist at General Dynamics Land Systems in Sterling Heights, Mich., from 2008-2010. Wilkerson received his master's degree in information assurance from the University of Detroit Mercy and his bachelor's degree in history from the University of Michigan. 


\section{REFERENCES}

1. $\quad$ Aparicio, A. F., Vela, F. L. G., Sánchez, J. L. G., \& Montes, J. L. I. (2012, October). Analysis and application of gamification. In Proceedings of the 13th International Conference on Interacción PersonaOrdenador (p. 17). ACM.

2. Bandura, A. (1997). Self-efficacy: The exercise of control. New York: Freeman

3. Burguillo, J. C. (2010). Using game theory and competition-based learning to stimulate student motivation and performance. Computers \& Education, 55(2), 566-575.

4. Wei, C. H. E. N. (2010). Security Measures Against the Hack Attacks and the Applications of Hackers' Technology. Journal of Hunan University of Science and Engineering, 7, 029.

5. Chentanez, N., Barto, A. G., \& Singh, S. P. (2004). Intrinsically motivated reinforcement learning. In Advances in neural information processing systems (pp. 1281-1288).

6. Chipman, S. F., \& Segal, J. W. (1985). Higher cognitive goals for education: An introduction. Thinking and learning skills: Research and open questions 2, 1-18.

7. Conklin, A. (2006, January). Cyber defense competitions and information security education: An active learning solution for a capstone course. In System Sciences, 2006. HICSS'06. Proceedings of the 39th Annual Hawaii International Conference on (Vol. 9, pp. 220b-220b). IEEE.

8. Cooper, S., Nickell, C., Pérez, L. C., Oldfield, B., Brynielsson, J., Gökce, A. G. \& Wetzel, S. (2010, June). Towards information assurance (IA) curricular guidelines. In Proceedings of the 2010 ITiCSE working group reports (pp. 49-64). ACM.

9. Deterding, S., Sicart, M., Nacke, L., O'Hara, K., \& Dixon, D. (2011, May). Gamification. using gamedesign elements in non-gaming contexts. InPART 2-Proceedings of the 2011 annual conference extended abstracts on Human factors in computing systems (pp. 2425-2428). ACM.

10. Engler, R. (2012). Serious Games-Gamification of Education.

11. Lam, S. F., Yim, P. S., Law, J. S., \& Cheung, R. W. (2004). The effects of competition on achievement motivation in Chinese classrooms. British Journal of Educational Psychology, 74(2), 281-296.

12. Lei, S. A. (2010). Intrinsic and extrinsic motivation: Evaluating benefits and drawbacks from college instructors' perspectives. Jorunal of Instructional Psychology, 37(2).

13. Merriam, S. B. (1998). Qualitative Research and Case Study Applications in Education. Revised and Expanded from" Case Study Research in Education". Jossey-Bass Publishers, 350 Sansome St, San Francisco, CA 94104.

14. Muntean, C. I. (2011, October). Raising engagement in e-learning through gamification. In Proc. 6th International Conference on Virtual Learning ICVL (pp. 323-329).

15. Ravitch, D. (2011). The death and life of the great American school system: How testing and choice are undermining education. Basic Books.

16. Ryan, R. M., \& Deci, E. L. (2000). Self-determination theory and the facilitation of intrinsic motivation, social development, and well-being. American psychologist, 55(1), 68

17. Nance, K., Taylor, B., Dodge, R., \& Hay, B. (2013). Creating Shareable Security Modules. In Information Assurance and Security Education and Training (pp. 156-163). Springer Berlin Heidelberg.

18. Schunk, D. H., Hanson, A. R., \& Cox, P. D. (1987). Peer-model attributes and children's achievement behaviors. Journal of Educational Psychology, 79(1), 54.

19. Seidman, I. (2012). Interviewing as qualitative research: A guide for researchers in education and the social sciences. Teachers college press

20. Sahlberg, P. (2011). Finnish lessons: What can the world learn from educational change in Finland. Teachers College Press.

21. Stockman, M., \& Nyland, J. (2010, October). A teaching pedagogy for networking/system administration courses: freshman through senior years. In Proceedings of the 2010 ACM conference on Information technology education (pp. 15-20). ACM.

22. Vesterbacka, P. (2013). Education Is for the (Angry) Birds. Scientific American, 309(2), 68-68.

23. Wagner, M. (2013). On The Gamification Of Education. Inted 2013 Proceedings, 2027-2034.

24. Zimmerman, B. J., \& Cleary, T. J. (2006). Adolescents' development of personal agency: The role of selfefficacy beliefs and self-regulatory skill. Self-efficacy beliefs of adolescents, 5, 45-69.

25. Zwaagstra, M. C., Clifton, R. A., \& Long, J. C. (2010). What's Wrong with Our Schools: And how We Can Fix Them. R\&L Education. 